\title{
The World Association for Psychosocial Rehabilitation
}

\author{
Angelo Barbato
}

President, World Association for Psychosocial Rehabilitation, Mario Negri Institute, Via Eritrea 62, 20157 Milan, Italy, email dirba@tin.it

\section{The primary aim of the WAPR is to provide to all stakeholders a forum for the ongoing discussion of the relevant issues concerning the long-term care of people with mental disorders.}

\begin{abstract}
he W orld Association for Psychosocial Rehabilitation (WAPR) could be considered as a newcomer among scientific societies in the mental health field, because it was established in 1986 in France, when about 100 professionals from 35 countries met at its founding congress. That congress was preceded by an extensive international planning process, which began with the First W orld Congress on Rehabilitation for the Mentally III in $\mathrm{H}$ elsinki, in 1970. Subsequent meetings of key professionals and agency representatives from various countries, mainly supported by the World $\mathrm{H}$ ealth $\mathrm{O}$ rganization (W HO) and the International Labour 0 ffice, resulted in the formation, in 1980, of a promoting group which planned, through its international secretariat, the foundation of the W APR. Therefore, close links with the mental health programme of the WHO have been maintained by the WAPR since its beginnings.

D r Benedetto Saraceno, the current director of the W HO 's D epartment of Mental Health and Substance Dependence, was President of the WAPR between 1993 and 1996. The present Executive Board is shown in Table 1.
\end{abstract}

Table 1. The WAPR Executive Board, 2003-06

\begin{tabular}{ll}
\hline Office & Current holder \\
\hline President & Angelo Barbato (Italy) \\
Immediate past President & Zebulon Taintor (USA) \\
President-Elect & M ichael Madianos (Greece) \\
Secretary General & Lourdes Ladrido-Ignacio (Philippines) \\
Treasurer & Ernesto M Mggia (Italy) \\
Vice-President & Ida Kosza (Hungary) \\
Vice-President & Ana Fernandes Pitta (Brazil) \\
\hline
\end{tabular}

Table 2. The WAPR Regional Vice-Presidents, 2003-06

\begin{tabular}{ll}
\hline WHO region & Vice-President \\
\hline Africa & Paul Sidandi (Botswana) \\
Americas & Humberto M artinez (USA) \\
Eastern Mediterranean & Haroon Rashid Chaudhry (Pakistan) \\
Europe & Edvard Hauff (Norway) \\
South East Asia & Thyloth Murali (India) \\
Western Pacific & Naotaka Shinfuku (Japan) \\
\hline
\end{tabular}

The growth of the WAPR in the following years reflected the increasing importance of the prevention and reduction of social disability as a framework for the long-term community care of people with severe mental disorders.

Today, the WAPR is recognised as a non-governmental organisation with consultative status with the $\mathrm{WHO}$, the U nited $\mathrm{N}$ ations (UN ) Economic and Social Council, and the International Labour O ffice. Moreover, it also maintains relations with the European Commission and the African Rehabilitation Institute.

\section{Organisational structure}

Currently, the WAPR has a 46-member International Board ofD irectors, which includes six past Presidents and a Regional Vice-President with one or more deputies for each of the six regions of the world, following the regional structure of the WHO (see Table 2). Moreover, the Board includes representatives of consumers, families and voluntary organisations, as well as permanent representatives located in Geneva and $\mathrm{N}$ ew York, to link with WHO and UN agencies. More than 80 national secretaries represent the same number of national chapters across the world.

Membership of the WAPR is open not only to mental health professionals but also to researchers of various disciplines, administrators, policy makers, consumers and their relatives, and advocacy associations. This is because the primary aim of the WAPR is to provide to all stakeholders a forum for the ongoing discussion of the relevant issues concerning the long-term care of people with mental disorders.

\section{Publications}

The WAPR publishes a quarterly Bulletin, while the International Journal of M ental $\mathrm{H}$ ealth, edited in N ew York by a WAPR past President, Martin Gittelman, serves as a medium for publication of scientific papers and conference proceedings related to various aspects of psychosocial rehabilitation. Local bulletins are published by several national branches, such as in Spain, South Africa and India.

\section{Mission and goals}

The mission of the WAPR is the dissemination of principles and practices of psychosocial rehabilitation. In the 
W HO /WAPR consensus statement jo intly endorsed in 1996, psychosocial rehabilitation is defined as a process that facilitates the opportunity for individuals impaired, disabled or handicapped by a mental disorder to reach their optimal level of functioning in the community. It implies both improving individuals' competencies and introducing environmental changes in order to improve their quality of life.

It is therefore clear that psychosocial rehabilitation is a complex and ambitious strategy encompassing many different sectors and levels, centred on the relation between the individual with a mental disability and society as a whole. In consequence, the bodies involved with psychosocial rehabilitation are varied, and their means and tools vary as well, depending on the geographic, cultural, economic, political, social and organisational characteristics of the settings in which care is provided.

Within this broad frame of reference, the WAPR's activities cover a number of areas:

o promotion of national and international legislation, policies and programmes to meet the basic and special needs of people with a mental illness

0 international exchange of experiences and best practices in the field of rehabilitation of mental disorders

o organisation of training opportunities for health professionals, to introduce strategies for psychosocial rehabilitation in specialist and primary health care services

o consultation to local, national and international agencies to promote improved care, rehabilitation and services for people with a mental illness

o educational programmes to ensure maximum public, professional and government understanding of the needs and rights of people with disabling mental illnesses

o enhancement of the development and organisation of consumers' and families' associations, and mutual and self-help groups of individuals and carers affected by disabling mental illnesses

o promotion of open dialogue among consumers, policy makers and professionals

o collaboration with the UN, the WHO and the International Labour $\mathrm{O}$ ffice, by supporting the strategies for the treatment and rehabilitation of people with a mental disability within a community-based care approach

o technical assistance to developing countries with regard to the funding and development of communitybased rehabilitation programmes

o research on innovative approaches to the integrated care of people with mental disorders

o definition of standards, benchmarks and quality improvement tools in relation to community care.

As can be seen, the WAPR is at the same time a scientific society, a multi-disciplinary professional organisation and an advocacy group. It will celebrate its twentieth birthday at its ninth congress, to be held in Athens in 0 ctober 2006. We will welcome everybody interested in fighting the disability related to mental disorders and raising the quality of life of people with mental illnesses.

\section{News and notes}

For contributions to this column, please contact Brian Martindale FRCPsych, Psychotherapy Department, John Conolly Wing, West London Mental Health NHSTrust, Uxbridge Road, Hanwell UB1 3EU, UK, email brian.martindale@wlmht.nhs.uk

\section{College Annual Meeting}

This meeting in $\mathrm{H}$ arrogate should be a special attraction to our international members. As well as the important overall focus on 'C aring for Carers', there will be our now 'traditional' full-day stream organised by the Board of International Affairs involving presentations from the $\mathrm{Col}$ lege International Groups. See www.rcpsych.ac.uk/2004.

\section{The 12th Congress of the Association of European Psychiatrists (AEP)}

14-18 April 2004, Geneva

A very attractive scientific programme will include:

o Interactive main sessions, on challenging issues directly relevant to the identity and future ofEuropean psychiatry (conflicts of interests; the role of psychodynamic psychotherapy in training and practice; community psychiatry - myth or reality?). Experts with opposing views will debate and the audience can vote

o M eet-the-expert sessions, in which leading European psychiatrists will interact, especially with younger psychiatrists

O High-quality symposia on many contemporary European research and clinical issues

o Continuing medical education courses

o Poster sessions

o Workshops debating ongoing research

The Congress website, for further information, is www.kenes.com/aep2004.

\section{Launch of South Asian Overseas Group in Sri Lanka}

The South Asian 0 verseas Group (SAO G) was launched on 19 August 2003, during an International Conference
Psychosocial rehabilitation implies both improving individuals' competencies and introducing environmental changes in order to improve their quality of life. 